\title{
Influence of the Structure and Experimental Surfaces Modifications of 2:1 Clay Minerals on the Adsorption Properties of Methylene Blue
}

\author{
Laura Pardo ${ }^{1}$, Juan Antonio Cecilia ${ }^{1}$ (D), Cristina López-Moreno ${ }^{2}$, Víctor Hernández ${ }^{2}$ (D), \\ Manuel Pozo ${ }^{3}$, María José Bentabol ${ }^{1}$ and Francisco Franco ${ }^{1, *}$ \\ 1 Departamento de Química Inorgánica, Cristalografía y Mineralogía, Facultad de Ciencias, Campus de \\ Teatinos s/n, Universidad de Málaga, 29071 Málaga, Spain; lpardo@uma.es (L.P.); jacecilia@uma.es (J.A.C.); \\ bentabol@uma.es (M.J.B.) \\ 2 Departamento de Química Física, Facultad de Ciencias, Campus de Teatinos s/n, Universidad de Málaga, \\ 29071 Málaga, Spain; cristinalm@uma.es (C.L.-M.); hernandez@uma.es (V.H.) \\ 3 Departamento de Geología y Geoquímica, Facultad de Ciencias, Universidad Autónoma de Madrid, \\ Campus de Cantoblanco, 28049 Madrid, Spain; manuel.pozo@uam.es \\ * Correspondence: ffranco@uma.es; Tel.: +34-952-136-644
}

Received: 4 July 2018; Accepted: 17 August 2018; Published: 19 August 2018

\begin{abstract}
In this work the adsorption capacities of methylene blue on $\mathrm{Mg}$-smectite and sepiolite and its derived material obtained after acid treatment and/or the addition of Fe at its surfaces are studied. Natural smectite with high Mg-content in its octahedral sheet (Mg-smectite) displays higher adsorption capacity than the sepiolite due to the ability of $\mathrm{Mg}$-smectite to expand the basal spacing to accommodate methylene blue cations between adjacent layers and the inability of sepiolite to adsorb these cations within the structural channels. The acid-activation of Mg-smectite causes a clear decrease in the adsorption capacity attributed to the partial loss of the interlayer positions by the loss of the octahedral sheet and subsequent formation of amorphous silica. Moreover, the adsorption of the Mg-smectite decreases even more when iron oxohydroxides species are incorporated in its interlayer spacing making inaccessible the interlayer active sites for the adsorption of methylene blue cations. On the contrary, the microwave-assisted acid treatment of sepiolite causes a slight increase in the adsorption capacity related with the dispersion of fibers. Nevertheless, contrary to that observed with Mg-smectite, higher increasing of adsorption capacities are obtained after the formation of new adsorption centers due to the incorporation of iron oxohydroxides species at the external surfaces of sepiolite.
\end{abstract}

Keywords: bentonite; Mg-smectite; sepiolite; adsorption; methylene blue

\section{Introduction}

Water is an indispensable resource for the existence of life in the planet. Among several water pollutants, industrial dyes have been considered an important issue worldwide [1]. Nowadays, dyes are used in a large number of applications such as in the textile industry in wool, silk, acrylic, leather, or nylon. In addition, dyes are frequently employed in the field of cosmetics or in food. Among $10-15 \%$ of these dyes are discharged into the water without pretreatment causing damage to the environment and also to the human health even at low concentrations [2,3].

Several processes have been proposed to bring down the dumping of dyes into the water such as aerobic or anaerobic digestion, oxidation, ozonation, membrane separation, reverse osmosis, sedimentation, precipitation, or flotation. These treatments show a high efficiency for low scale or low proportion of dye; however, most of them are not competitive for larger proportions of dyes [4,5]. 
The use of inexpensive and available materials with high adsorption capacity is a sustainable alternative to retain pollutants coming from contaminated water [5]. Considering these premises, clay minerals have emerged as interesting materials owing to their high availability on the Earth's surface and their thermochemical stability in a wide range of $\mathrm{pH}$ [6-8]. The capability of clay minerals to change their exchangeable cations by other cations more harmful to the environment, which are dissolved in the water, together with their ability to establish electrostatic interactions by hydrogen bonds between the clay mineral and the dye confers good adsorbent properties to these minerals, being adequate candidates to be used in many processes of environmental remediation [6].

Both smectite and sepiolite are clay minerals belonging to phyllosilicates group with many industrial applications. The physicochemical behavior on these materials depends of their structure and grain size, frequently smaller than $2 \mu \mathrm{m}$.

The smectite group of clay minerals consists of several species whose structure is based on the stacking of negatively charged 2:1 layers. These 2:1 layers are formed by two continuous tetrahedral sheets $(\mathrm{T})$ with $\left[\mathrm{SiO}_{4}\right]^{4-}$ tetrahedral linked to adjacent tetrahedral molecules by sharing three corners, obtaining a bidimensional pattern with hexagonal structure along the $a, b$ plane. An octahedral sheet (O) is located between these two T-sheets. They can be either dioctahedral or trioctahedral, depending on whether the octahedral sheet is fully filled with divalent $\left(\mathrm{Mg}^{2+}\right.$ and $\left.\mathrm{Fe}^{2+}\right)$ or partially filled with trivalent cations $\left(\mathrm{Al}^{3+}\right.$ and $\left.\mathrm{Fe}^{3+}\right)$. The negative charge of these 2:1 layers is balanced by hydrated exchangeable cations which are located in interlayer positions (mostly $\mathrm{Ca}^{2+}, \mathrm{Mg}^{2+}$, and $\mathrm{Na}^{+}$) [9].

The main species of dioctahedral smectites include aluminum smectites as montmorillonite $\left(\mathrm{M}_{\mathrm{x} / \mathrm{n}}{ }^{\mathrm{n}+}\left[\mathrm{A}_{4-\mathrm{x}} \mathrm{Mg}_{\mathrm{x}}\right]\left[\mathrm{Si}_{8}\right] \mathrm{O}_{20}(\mathrm{OH})_{4} \cdot \mathrm{nH}_{2} \mathrm{O}\right)$ [9] where the negative layer charge results from divalent cations replacing $\mathrm{Al}^{3+}$ cations in the octahedral sites. On the other hand the most important trioctahedral smectites are saponite, where the negative layer charge results from trivalent cations replacing $\mathrm{Si}^{4+}$ cations in the tetrahedral sites $\left(\mathrm{M}_{\mathrm{x} / \mathrm{n}}{ }^{\mathrm{n}+}\left[\mathrm{Mg}_{6}\right]\left[\mathrm{Si}_{8-\mathrm{x}} \mathrm{Al}_{\mathrm{x}}\right] \mathrm{O}_{20}(\mathrm{OH})_{4} \cdot \mathrm{nH}_{2} \mathrm{O}\right)$, and stevensite, where the layer charge is interpreted as due to vacancies in octahedral positions $\left(\mathrm{M}_{\mathrm{x} / \mathrm{n}}{ }^{\mathrm{n}+}\left[\mathrm{Mg}_{6-\mathrm{x}}\right.\right.$ vacancy $\left.\left._{\mathrm{x}}\right]\left[\mathrm{Si}_{8}\right] \mathrm{O}_{20}(\mathrm{OH})_{4} \cdot \mathrm{nH}_{2} \mathrm{O}\right)[9]$.

Sepiolite is a fibrous phyllosilicate, whose chemical formula is $\mathrm{Si}_{12} \mathrm{O}_{30} \mathrm{Mg}_{8}(\mathrm{OH})_{4}\left(\mathrm{OH}_{2}\right)_{4} \cdot 8 \mathrm{H}_{2} \mathrm{O}$. Sepiolite structure is formed by sheets similar to those observed in the smectites, but the tetrahedra undergoes a periodic inversion (every 6 tetrahedra) along the $b$ axis, leading to channels with a dimensions of $3.6 \AA \times 10.6 \AA$ [10], which contains both physisorbed and zeolitic water [11,12]. The structure of sepiolite gives rise to materials with a high adsorption capacity both on the fiber surfaces as well as into the nanochannels.

The physicochemical properties of the clay minerals can be modified by several methods such as the insertion of polyoxocations and pillars [13,14] or by means of acid treatment [15-19], increasing the specific surface area and the pore volume of the clays minerals. Franco et al. have shown that, except for $\mathrm{Hg}(\mathrm{II})$, the $\mathrm{Fe}(\mathrm{III})$-homoionic smectites display higher metal adsorption properties than that of activated carbon used previously [20]. Recently, it has been established the effectiveness of microwave-assisted acid treatment, obtaining a high modification in their textural properties in short irradiation times [17-19]. The use of microwave-assisted acid treatment (MAT) in the acid activation of clay minerals offers advantages over traditional methods including a higher heating rate that reduces the treatment time from 2 days to $16 \mathrm{~min}[17,18]$. Recent studies on MAT of sepiolites and trioctahedral smectites point out the relevance of structural ordering and composition of octahedral sheet in the reactivity of these clay minerals to this type of acid treatment. In the case of sepiolite lower crystallinity and higher proportions of $\mathrm{Mg}^{2+}$ in the octahedral sheets increases the reactivity to MAT [17], whereas the chemical composition of the octahedral sheets, in the case of smectites, appears to be the main factor controlling the reactivity to MAT [18].

The aim of this work is assess the effect of microwave assisted acid treatment on the adsorption capacity of two clays with high Mg-content in the octahedral sheet (Mg-clays); one composed of Mg-smectite the other of sepiolite. The adsorption capacity of these clay materials have been evaluated using methylene blue. This cation is usually used to evaluate the sorption properties of clay 
minerals [21,22]. Nevertheless, in this work we use methylene blue in order to study the effect of the structure of starting clay minerals and its experimental modifications in the adsorption properties.

\section{Materials and Methods}

\subsection{Materials}

The study reported in the present work was carried out using a Mg-bentonite, supplied by TOLSA, with the commercial name ESMEGEL (Sm), and a raw sepiolite (Sp), both coming from the Madrid Basin deposits (Spain). The dye used in this research was methylene blue $\left(\mathrm{C}_{16} \mathrm{H}_{18} \mathrm{ClN}_{3} \mathrm{~S}\right)$ (99\%, Sigma-Aldrich). The gases evolved in the determination of the textural properties of the natural clay minerals and the obtained materials were $\mathrm{He}$ (Air Liquide 99.99\%) and $\mathrm{N}_{2}$ (Air Liquide 99.9999\%).

\subsection{Microwave-Assisted Acid Treatment}

The starting materials were modified by a microwave-assisted acid treatment following the methodology described previously $[17,18]$. In each microwave-assisted treatment, $5 \mathrm{~g}$ were treated with $50 \mathrm{~mL}$ of a nitric acid solution $(0.2 \mathrm{~N})$ for $8 \mathrm{~min}$, using a microwave system EMS20100OX (Electrolux, Stockholm, Sweden), operating at $800 \mathrm{~W}$ and $2.45 \mathrm{GHz}$. In order to avoid exceeding a temperature higher than $100{ }^{\circ} \mathrm{C}$ in the system, the microwave irradiation was applied in a discontinuous form. Thus, after $1 \mathrm{~min}$ of microwave irradiation the suspensions were cooled for $5 \mathrm{~min}$ at room temperature. Then, samples were centrifuged and washed with deionized water until the complete removal of $\mathrm{NO}_{3}{ }^{-}$ions, as determined the Griess test. Finally, the samples modified by microwave-assisted acid treatment were dried overnight.

\subsection{Iron Oxide Supported Clay Minerals}

$\mathrm{Fe}(\mathrm{III})$ exchanged-smectite was prepared through the slow addition of a $0.2 \mathrm{M} \mathrm{FeCl}_{3} \cdot 6 \mathrm{H}_{2} \mathrm{O}$ solution on the clay mineral dispersion in a proportion of $2 \mathrm{~m}_{\mathrm{eq}} \cdot \mathrm{g}^{-1}$ of the starting smectites, stirring for $4 \mathrm{~h}$ at room temperature. After centrifugation, the Fe-smectites were washed by dialysis until chloride ions $\left(\mathrm{AgNO}_{3}\right.$ test) elimination. Finally, samples were heated at $300^{\circ} \mathrm{C}$ for $2 \mathrm{~h}$.

\subsection{Characterization}

Powder patterns for the whole samples were collected on an X'Pert Pro MPD automated diffractometer (PANalytical B.V., Almelo, The Netherlands) equipped with a Ge(111) primary monochromator (strictly monochromatic $\mathrm{CuK} \alpha 1$ radiation. PANalytical B.V., Almelo, The Netherlands) and an X'Celerator detector (PANalytical B.V., Almelo, The Netherlands). The overall measurement time was 33 min per pattern in order to obtain very good statistics over the $2 \theta$ range of $2-65^{\circ}$ with $0.017^{\circ}$ step size.

The X-ray fluorescence analysis (XRF) (major elements) of untreated and activated samples was performed using the MagiX X-ray fluorescence spectrometer of PANanytical (PANalytical B.V., Almelo, The Netherlands). Sodium was determined with an atomic absorption (AA) spectrophotometer (Varian 220-FS QU-106, Varian Inc., Palo Alto, CA, USA).

DRIFT spectra were collected on a Harrick HVC-DRP cell fitted to a Varian 3100 FT-IR spectrophotometer. The interferograms consisted of 200 scans with a resolution of $4 \mathrm{~cm}^{-1}$, and the spectra were collected using a $\mathrm{KBr}$ spectrum as a background. About $30 \mathrm{mg}$ of finely ground clay-based materials were placed in the sample holder.

The textural parameters were evaluated from $\mathrm{N}_{2}$ adsorption-desorption isotherms at $-196{ }^{\circ} \mathrm{C}$, as determined by an automatic ASAP 2020 system from Micromeritics. Prior to the measurements, samples were outgassed at $120^{\circ} \mathrm{C}$ and $10^{-4}$ mbar overnight. The specific surface areas (SBET) were determined through the BET equation [23], assuming a cross-section of $0.162 \mathrm{~nm}^{2}$ for the $\mathrm{N}_{2}$ molecule. The micropore area and micropore volume were determine from the t-plot method [24]. 
The shape and size of the starting samples were examined by scanning electron microscope (SEM) using a JEOL SM-6490 LV (Peabody, MA, USA). The samples for SEM observation were previously gold sputtered (10 $\mathrm{nm}$ thick) in order to avoid charging of the surface.

\subsection{Batch Experiments}

The kinetic adsorption experiments were carried out by stirring $0.1 \mathrm{~g}$ of sample in a solution of $100 \mathrm{~mL}$ with methylene blue $\left(80 \mathrm{mg} \cdot \mathrm{L}^{-1}\right)$. The $\mathrm{pH}$ was maintained at 7 in all sorption experiments using small amounts of $0.1 \mathrm{~N} \mathrm{HNO}_{3} / \mathrm{NaOH}$ in a beaker agitated vigorously by a magnetic stirrer at $400 \mathrm{rpm}$ using a water bath maintained at a constant temperature $25^{\circ} \mathrm{C}$. After each experiment, samples were collected and centrifuged for $3 \mathrm{~min}$ at $5000 \mathrm{rpm}$ and then measured by UV-Vis absorbance using a wavelength of $666 \mathrm{~nm}$, using a UV-Vis spectrophotometer Agilent 8453. The kinetic experiments were carried out between 1 and $20 \mathrm{~min}$ for the Mg-bentonite, while adsorption times between 5 and $120 \mathrm{~min}$ were used to the kinetic studies for the sepiolite.

For the measurement of the adsorption isotherms, different initial concentrations of methylene blue were used (10 to $100 \mathrm{mg} \cdot \mathrm{L}^{-1}$ ), using a clay weight of $0.03 \mathrm{~g}$ and equilibrium time of $10 \mathrm{~min}$ for Mg-bentonite and $0.1 \mathrm{~g}$ and equilibrium time of $1 \mathrm{~h}$ for sepiolite. In all experiments, after the contact time, aliquots were collected and centrifuged. In the supernatant the dye concentration was analyzed by UV-Vis absorbance, using a wavelength of $666 \mathrm{~nm}$.

\section{Results and Discussion}

\subsection{X-ray Diffraction}

The X-ray diffraction patterns of the Mg-bentonite and sepiolite are shown in Figure 1. $\mathrm{Mg}$-bentonite sample (Sm) (Figure 1a) shows the presence of minor proportions of quartz, calcite, and dolomite, whereas only traces of calcite are identified in sepiolite (Sp) (Figure 1b). Mg-bentonite shows a wide 001 reflection band with two maxima suggesting the presence of at least two types of interlayer cations and/or a great variability in the hydration degree in interlayer space. The XRD reflections of sepiolite are sharp and well-defined in comparison to those displayed by Mg-bentonite, indicating a higher ordered structure for the fibrous clay mineral. The study of the clay fraction of the $\mathrm{Mg}$-bentonite (oriented aggregates method) indicates the predominance of $\mathrm{Mg}$-smectite and traces of sepiolite.

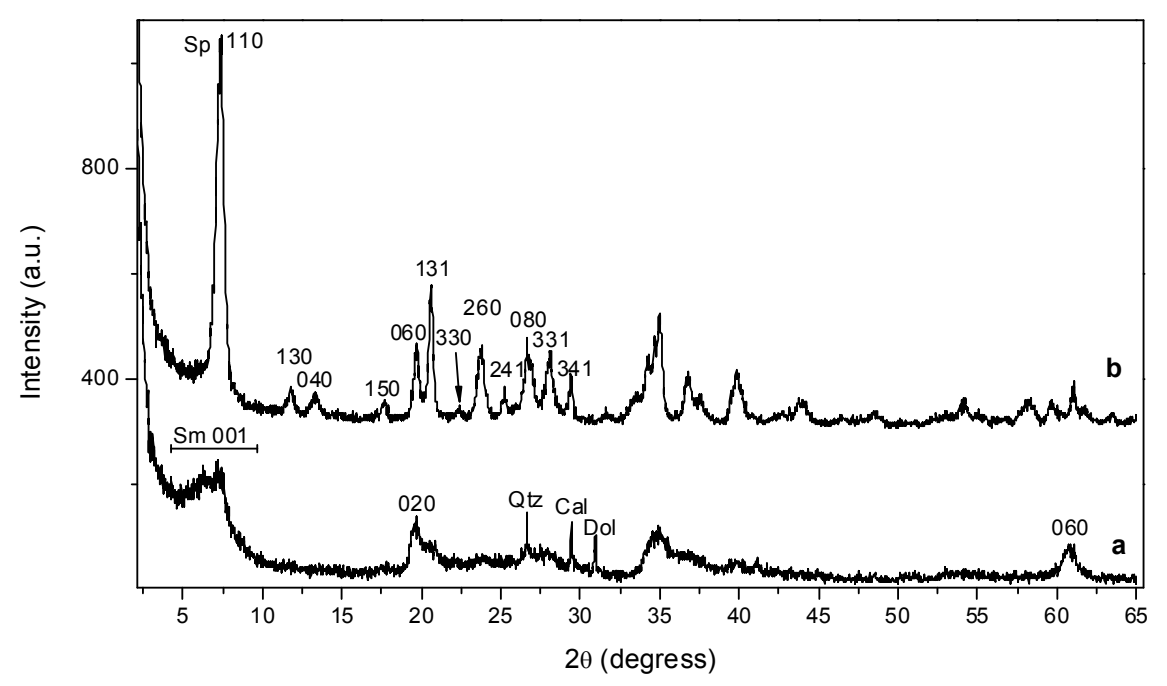

Figure 1. XRD patterns of starting Sm (a) and Sp (b). 
XRD profile of the Mg-bentonite after the microwave-assisted acid treatment $(\mathrm{Sm}-\mathrm{H})$ reveals the disappearance of the diffraction reflections (Figure 2(Ia,Ib)) attributed to calcite and dolomite due to the dissolution of these carbonates after $8 \mathrm{~min}$ of acid treatment. Moreover, the intensity of the (001) and (020) diffraction reflections notably decreases suggesting the partial alteration of the $\mathrm{Mg}$-smectite structure. On the other hand, the crystallinity of the quartz seems to be maintained after the microwave-assisted acid treatment.

The comparison between the XRD patterns of the raw sepiolite (Sp) and the material obtained after the microwave acid treatment also shows modifications (Sp-H) (Figure 2(IIa,IIb)). Generally, a decrease in the intensity of the diffraction lines is noticeable, especially the (110) reflection. In addition, the occurrence of a broad band in the range of 15 to $33^{\circ}(2 \theta)$ can be also observed. Both facts suggest that sepiolite structure is sensibly affected with the acid treatment and that the formation of an amorphous silica phase can take place [17].
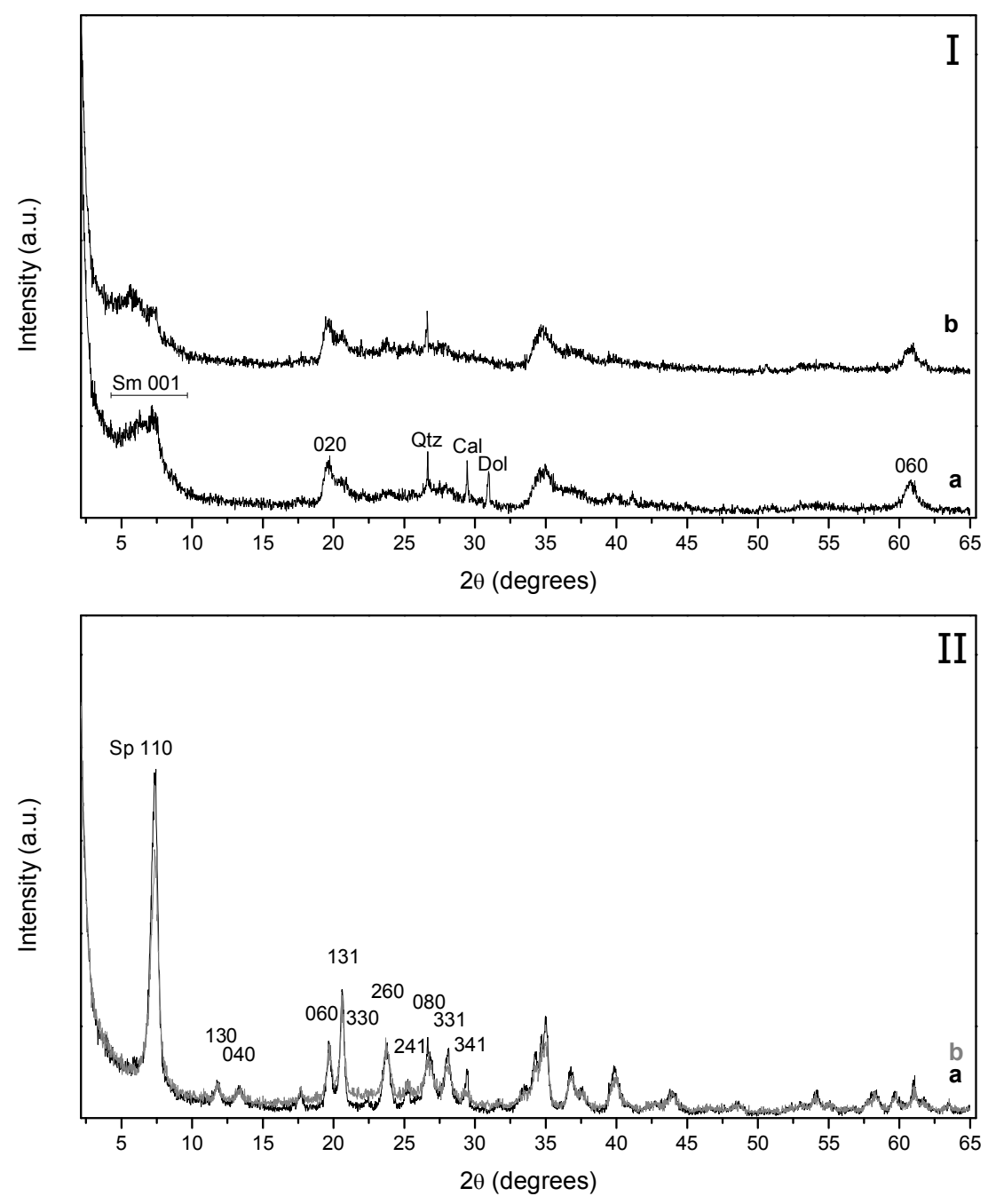

Figure 2. (I): XRD patterns of starting Sm (a) and Sm-H (b). (II): Comparison of XRD patterns of starting Sp (a, black) and Sp-H (b, grey).

The incorporation of iron species into the starting $\mathrm{Mg}$-smectite ( $\mathrm{Fe}-\mathrm{Sm})$ and that modified by acid treatment $(\mathrm{Fe}-\mathrm{Sm}-\mathrm{H})$ also causes changes in the XRD profile (Figure 3I). As it took place for the sample modified by the microwave-assisted acid treatment, the diffraction peaks attributed to carbonate minerals disappears from the XRD diffraction patterns after the treatment with $\mathrm{Fe}^{3+}$ (Figure 3(Ia)), since the $\mathrm{FeCl}_{3}$ solution is enough acidic $(\mathrm{pH} \sim 1)$ to dissolve the carbonate species. In addition, 
the (001) diffraction displays two peaks located at 9.8 and $11.8 \AA$, which suggests the coexistence of a different hydration state and/or interlayer cations [18]. Moreover, we must take into account that the intensity of this last reflection is affected by the presence of minor amounts of sepiolite. On the contrary, the comparison of the XRD diffraction patterns of the Fe-treated sepiolites suggests that the incorporation of $\mathrm{Fe}^{3+}$ within the raw sepiolite $(\mathrm{Fe}-\mathrm{Sp})$ and in the acid activated sepiolite $(\mathrm{Fe}-\mathrm{Sp}-\mathrm{H})$ has no noticeably effect on their structure (Figure 3II).
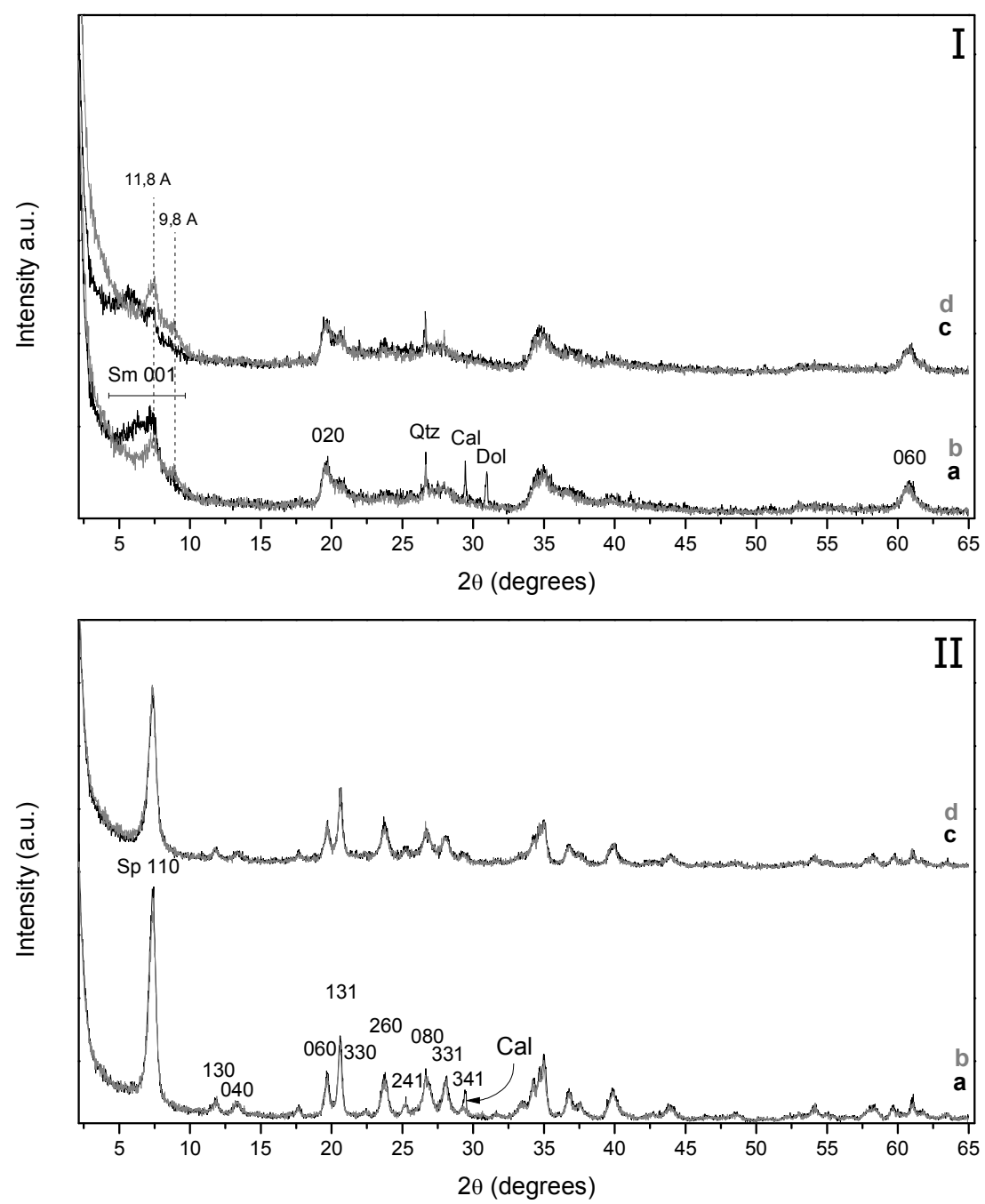

Figure 3. (I) Comparison of XRD patterns of starting Sm (a, black), Fe-Sm (b, grey), Sm-H (c), and $\mathrm{Fe}-\mathrm{Sm}-\mathrm{H}$ (d, grey), (II) Comparison of XRD patterns of starting Sp (a, black), Fe-Sp (b, grey), Sp-H (c), and $\mathrm{Fe}-\mathrm{Sp}-\mathrm{H}$ (d, grey).

\subsection{Chemical Analysis (XRF)}

The chemical composition of the studied materials was determined by XRF. From data reported in Table 1, it can be observed the predominance of magnesium which is coherent with the trioctahedral character of the clay minerals. The content of $\mathrm{K}, \mathrm{Ca}$, and $\mathrm{Na}$, must be related with the presence of exchangeable cations although the content of $\mathrm{Ca}$ in $\mathrm{Mg}$-smectite is also due to carbonates. Chemical analysis data (Table 1) also reveal that microwave-assisted acid treatment produces a remarkable decrease of the magnesium content in both $\mathrm{Mg}$-smectite and sepiolite, while the $\mathrm{Si}, \mathrm{Al}$, and $\mathrm{Fe}$ content are maintained after the acid treatment. This implies a partial dissolution of the octahedral sheet, releasing amorphous and insoluble silica, as was indicated for the XRD profile. In the same way, it is also noticeable the decrease of Ca content, which confirms the dissolution of the calcite phase as 
well as the $\mathrm{Ca}^{2+}$ species located in the interlayer space, which must be replaced by $\mathrm{H}^{+}$species. With regard to potassium, the chemical data show similar values after the acid treatment, indicating that this cation remain in the interlayer space after the treatment.

Table 1. Chemical analysis of starting and treated Sm and Sp (wt \%).

\begin{tabular}{ccccccccccc}
\hline Sample & $\mathbf{S i O}_{\mathbf{2}}$ & $\mathbf{A l}_{\mathbf{2}} \mathbf{O}_{\mathbf{3}}$ & $\mathbf{M g O}$ & $\mathbf{F e}_{\mathbf{2}} \mathbf{O}_{\mathbf{3}}$ & $\mathbf{N a}_{\mathbf{2}} \mathbf{O}$ & $\mathbf{K}_{\mathbf{2}} \mathbf{O}$ & $\mathbf{C a O}$ & $\mathbf{M n O}$ & $\mathbf{P}_{\mathbf{2}} \mathbf{O}_{\mathbf{5}}$ & $\mathbf{T i O}_{\mathbf{2}}$ \\
\hline $\mathrm{Sm}$ & 56.06 & 4.84 & 21.45 & 1.44 & 0.146 & 0.726 & 2.72 & 0.0442 & 0.11 & 0.156 \\
$\mathrm{Sm}-\mathrm{H}$ & 57.05 & 4.7 & 16.16 & 1.55 & 0 & 0.745 & 0.366 & 0.035 & 0 & 0.171 \\
$\mathrm{Fe}-\mathrm{Sm}$ & 57.99 & 5.85 & 21.39 & 4.56 & 0.154 & 0.884 & 1.12 & 0.0585 & 0.111 & 0.181 \\
$\mathrm{Fe}-\mathrm{Sm}-\mathrm{H}$ & 64.65 & 5.02 & 17.35 & 4.18 & 0.137 & 0.78 & 0.0834 & 0.0338 & 0.0594 & 0.177 \\
$\mathrm{Sp}$ & 61.67 & 1.67 & 21.8 & 0.537 & 0.208 & 0.222 & 0.952 & 0.0318 & 0.0087 & 0.0617 \\
$\mathrm{Sp}-\mathrm{H}$ & 65.57 & 1.46 & 16.44 & 0.547 & 0.0627 & 0.206 & 0.104 & 0.0261 & 0 & 0.0637 \\
$\mathrm{Fe}-\mathrm{Sp}$ & 62.38 & 1.64 & 21.41 & 3.09 & 0 & 0.204 & 0.0307 & 0.0305 & 0.0231 & 0.0634 \\
$\mathrm{Fe}-\mathrm{Sp}-\mathrm{H}$ & 69.07 & 1.46 & 16.43 & 1.58 & 0 & 0.199 & 0.0115 & 0.0211 & 0.0076 & 0.0645 \\
\hline
\end{tabular}

The chemical analysis of the sample treated with $\mathrm{FeCl}_{3}$ solution shows little effect how the acid treatment does not seem to affect to the $\mathrm{Fe}^{3+}$ species incorporated, being in the same range for the raw $\mathrm{Mg}$-smectite (4.56 wt \% $\mathrm{Fe}_{2} \mathrm{O}_{3}$ ) and the $\mathrm{Mg}$-smectite treated by acid treatment $\left(4.18 \mathrm{wt} \% \mathrm{Fe}_{2} \mathrm{O}_{3}\right)$. In the case of sepiolite, the treatment of the raw sepiolite with the $\mathrm{FeCl}_{3}$ solution display higher $\mathrm{Fe}_{2} \mathrm{O}_{3}$ content ( $3.09 \mathrm{wt} \%)$ than that modified by acid treatment (1.58 wt \%). The lower iron values could be ascribed to the formation of amorphous silica, which can cause a decrease in the adsorption capacity.

\subsection{Scanning Electronic Microscopy (SEM)}

SEM micrograph of starting Mg-smectite (Sm) (Figure 4a) shows that individual particles of this mineral have sizes ranging between 1 and $5 \mu \mathrm{m}$ and are grouped into aggregates in the range between 4 and $10 \mu \mathrm{m}$. Figure $4 \mathrm{~b}$ shows that $8 \mathrm{~min}$ of microwave assisted acid treatment $(\mathrm{Sm}-\mathrm{H})$ causes a strong dispersion of the aggregate in individual lamellar particles of sizes smaller than $1 \mu \mathrm{m}$. SEM images reveal that the starting $\mathrm{Mg}$-smectite does not change after treating with $\mathrm{Fe}^{3+}$ solutions $(\mathrm{Fe}-\mathrm{Sm})$. Minor dispersions are observed compared with the acid activated Mg-smectite (Sm-H) (Figure 4c). Nevertheless, although the aggregates seem to be slightly larger than those observed in the Sm-H sample, the individual lamellar particles of Fe-Sm-H appears to be smaller than the previous ones.

Figure 5a, shows the typical fibrous habit of sepiolite forming aggregates with a maximum length of $40 \mu \mathrm{m}$. After the acid treatment, the fibers of sepiolite (Sp) (Figure $5 \mathrm{~b}$ ) appear more disaggregated (Figure 4c,d) with a length more homogeneous and slightly smaller when compared with those of the starting sepiolite. These similar observations can be made in the SEM micrograph of Fe-Sm (Figure 5c). On the other hand, the length of the fibers of the Fe-Sp-H are even smaller than those described above for the acid activated sepiolite and for the Fe-Sp. 

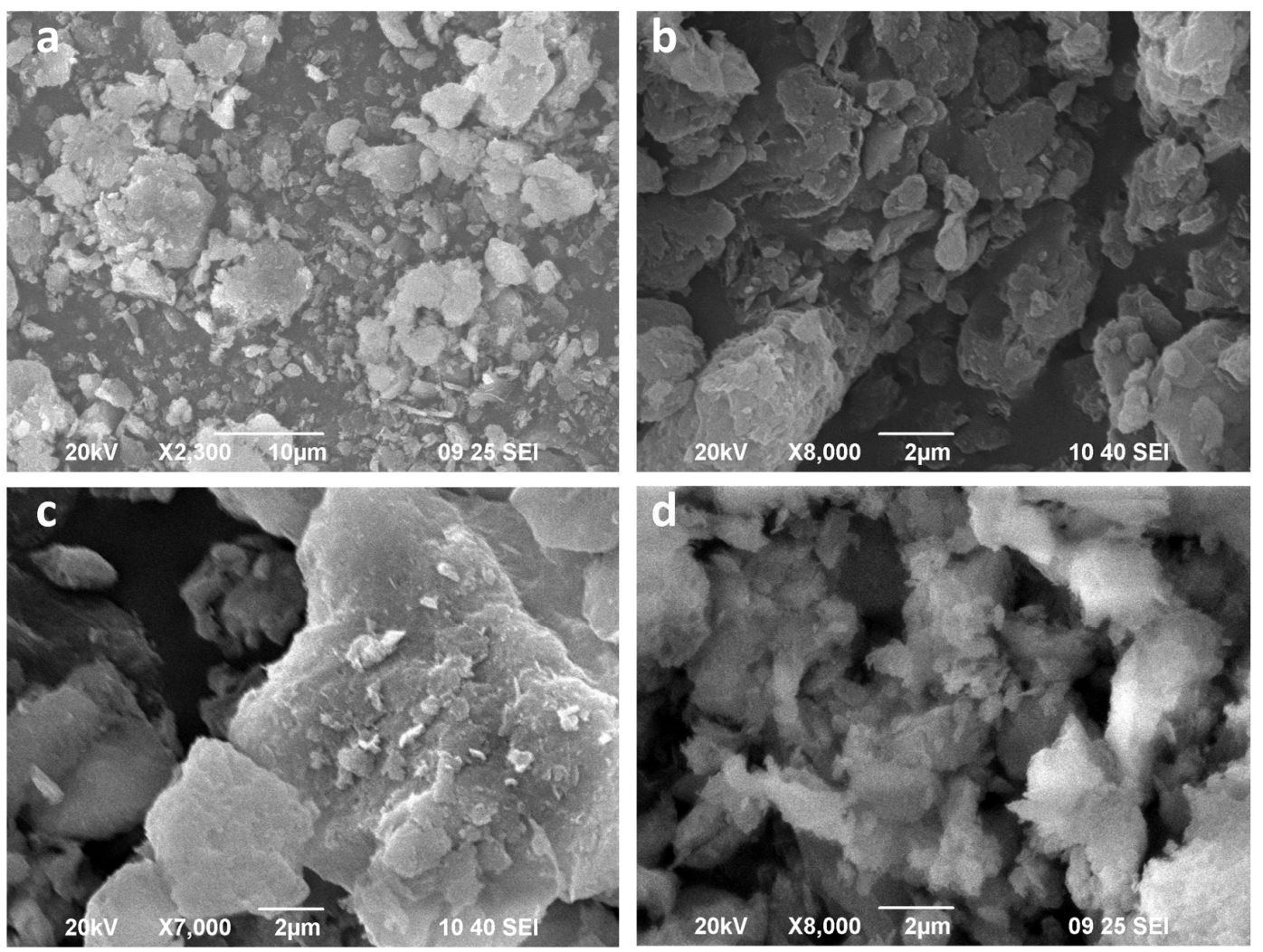

Figure 4. SEM micrographs of natural $\mathrm{Sm}(\mathbf{a}), \mathrm{Sm}-\mathrm{H}(\mathbf{b}), \mathrm{Fe}-\mathrm{Sm}(\mathbf{c})$, and $\mathrm{Fe}-\mathrm{Sm}-\mathrm{H}(\mathbf{d})$.
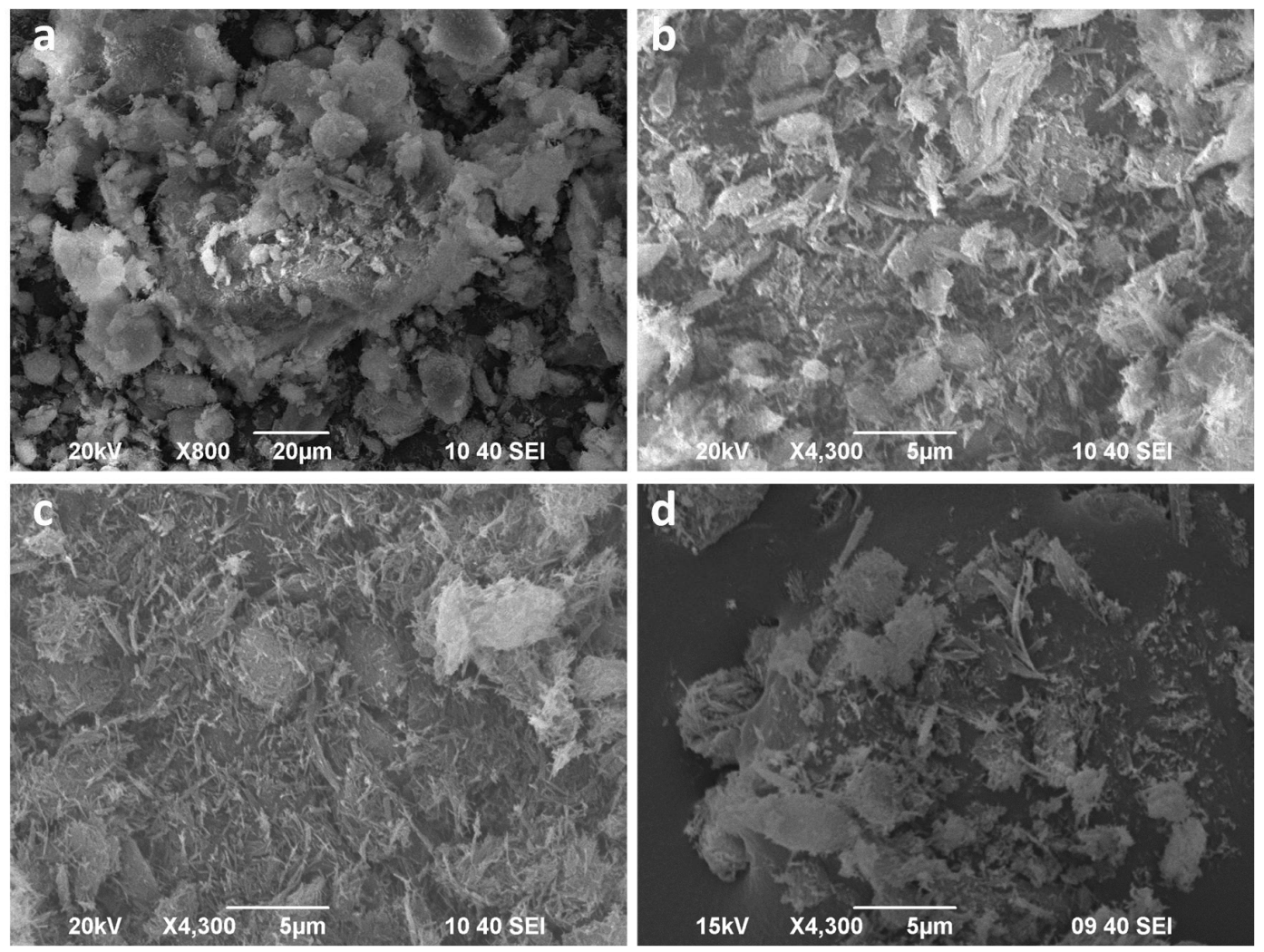

Figure 5. SEM micrographs of natural Sp (a), Sp-H (b), Fe-Sp (c), and Fe-Sp-H (d). 


\subsection{Nitrogen Adsorption}

The specific surface area was determined from the $S_{B E T}$ equation [23] (Table 2). The natural sepiolite displays a $\mathrm{S}_{\mathrm{BET}}$ value of $308 \mathrm{~m}^{2} \cdot \mathrm{g}^{-1}$, while the starting Mg-smectite displays a $\mathrm{S}_{\mathrm{BET}}$ of $182 \mathrm{~m}^{2} \cdot \mathrm{g}^{-1}$. Sepiolite displays microporosity ascribed to the channels formed by the reversal of the tetrahedral layer [10]. The microporosity of Mg-smectite can be related with its low structural ordering, which can generate small cavities leading to this microporosity. In all cases, it can be observed an increase of the $\mathrm{N}_{2}$ adsorbed at high relative pressure, indicating the presence of macroporosity ascribed to the presence of interparticle voids as was shown from the SEM images.

The acid treatment causes a clear increase of the $S_{\text {BET }}$ values, microporosity and mesoporosity,

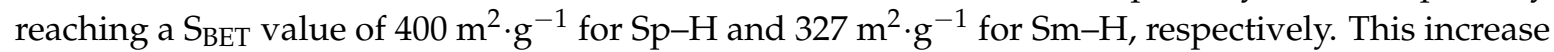
is directly related with the partial loss of the $\mathrm{Mg}^{2+}$ cations located in the octahedral sheet and the formation of amorphous silica along the microwave-assisted acid treatment, as indicated by the XRF data (Table 1).

Table 2. Specific surface areas $\left(\mathrm{m}^{2} \cdot \mathrm{g}^{-1}\right)$ of the natural clays and the obtained materials.

\begin{tabular}{ccccccccc}
\hline Sample & Sm & Fe-Sm & Sm-H & Fe-Sm-H & Sp & Fe-Sp & Sp-H & Fe-Sp-H \\
\hline Smicro & 92 & 138 & 164 & 170 & 182 & 169 & 218 & 199 \\
S $_{\text {ext }}$ & 90 & 96 & 163 & 131 & 126 & 130 & 182 & 180 \\
S $_{\text {BET }}$ & 182 & 234 & 327 & 301 & 308 & 299 & 400 & 379 \\
\hline
\end{tabular}

The incorporation of iron species from $\mathrm{Fe}^{3+}$ solution and subsequent calcination displays different behavior in Mg-smectite and sepiolite. Thus, both sepiolites ( $\mathrm{Sp}$ and $\mathrm{Sp}-\mathrm{H}$ ) suffer a decrease in the $\mathrm{S}_{\mathrm{BET}}$ value attributed to a slight decrease of its microporosity, probably since iron species (in Fe-Sp and $\mathrm{Fe}-\mathrm{Sp}-\mathrm{H})$ can be located within the channels of the sepiolite. In the case of the Mg-smectite, the incorporation of the iron species causes an increase of the surface attributed to the microporosity. This fact suggests that iron species are not blocking the porosity of the structure but rather favors the formation of higher proportion of micropores by the formation of a pillared structure, as was suggested by XRD data. The incorporation of iron species after the acid treatment in the Mg-smectite leads to a slightly higher microporosity and a slightly lower external surface probably due to the formation of larger aggregates, as was shown in the SEM images.

\subsection{DRIFT Analysis}

Figure 6I-A shows the $3750-3000 \mathrm{~cm}^{-1}$ region of the DRIFT spectra of the starting $\mathrm{Mg}$-smectite $(\mathrm{Sm})$. The position of the $\mathrm{O}-\mathrm{H}$ stretching bands is notably influenced by the chemical compositions of the octahedral sheet [25]. For this reason, there are many differences related with both the number and the positions of the $\mathrm{O}-\mathrm{H}$ stretching band in the DRIFT spectra of the natural di- and trioctahedral smectites. Regarding Sm (Figure 6I-A), the O-H stretching bands appear at higher wavenumbers compared to those of dioctahedral smectites. In this case, the $\mathrm{O}-\mathrm{H}$ stretching region is characterized by the presence three overlapping bands centered at 3681,3619, and $3554 \mathrm{~cm}^{-1}$.

The band at $3681 \mathrm{~cm}^{-1}$ is classically assigned to the $\mathrm{O}-\mathrm{H}$ stretching mode of structural $\mathrm{Mg}(\mathrm{OH})_{2}$ groups in the octahedral sheet of Sm structure [26-28]. Regarding the band at $3619 \mathrm{~cm}^{-1}$, it can be assigned to the $\mathrm{O}-\mathrm{H}$ stretching modes of AlOHSi groups formed by isomorphous substitutions of $\mathrm{Si}(\mathrm{IV})$ by $\mathrm{Al}(\mathrm{III})$ in the tetrahedral sheet of Sm [18]. Moreover, DRIFT the band at $3554 \mathrm{~cm}^{-1} \mathrm{can} \mathrm{be}$ assigned to the AlOHMg and $\mathrm{MgOHFe}$ stretching vibrations [29]. The DRIFT spectrum of the starting Sm also shows water-stretching vibrations bands at 3379 and $3242 \mathrm{~cm}^{-1}[26,30]$.

The Si-O stretching region of DRIFT spectra of the untreated Sm is shown in Figure 6II-B(a). The di- or trioctahedral nature of the starting mineral apparently influences the position of the Si-O stretching band in the DRIFT spectrum [26]. The Si-O stretching band appears centered at $963 \mathrm{~cm}^{-1}$ in the starting Mg-smectite. This band is classically assigned to the in-plane, $v(\mathrm{Si}-\mathrm{O})$ mode [31]. 
Moreover, in both starting smectites the in-plane $\mathrm{Si}-\mathrm{O}$ stretching band is accompanied by a small band at $1090 \mathrm{~cm}^{-1}$ which is ascribed to the out-of-plane Si-O stretching modes [29]. On the other hand, the band at $1632 \mathrm{~cm}^{-1}$ is related with the adsorbed water bending modes and the bands at 1644 and $1410 \mathrm{~cm}^{-1}$ to carbonates [30], while the band at $881 \mathrm{~cm}^{-1}$ is related with the deformation modes of OH-Mg [29]. The band located about $655 \mathrm{~cm}^{-1}$ is attributed to $\mathrm{Mg}_{3} \mathrm{OH}$ bending vibrations [26]. Moreover, the absence of bands located about 916 and $844 \mathrm{~cm}^{-1}$ assigned to $\left(\mathrm{Al}_{2} \mathrm{OH}\right)$ and (AlOHMg) [26], respectively, confirms the low content of Al-species in the clay mineral, which is in agreement with the chemical analysis, shown in Table 1.

The $\mathrm{O}-\mathrm{H}$ stretching region of acid activated $\mathrm{Mg}$-smectite $(\mathrm{Sm}-\mathrm{H})$ is shown in Figure 6I-A(b). A general decrease in the intensity of the $\mathrm{O}-\mathrm{H}$ bands and water stretching bands $(3379,3242)$ is observed in the first $8 \mathrm{~min}$ of treatment and a new band appears at $3710 \mathrm{~cm}^{-1}$. This band is commonly observed in the DRIFT spectra of the acid activated smectites and related with the $\mathrm{O}-\mathrm{H}$ stretching mode of Si-OH groups [32]. Moreover, the OH-Mg deformation band and carbonate bands disappear after $8 \mathrm{~min}$ of microwave-assisted acid treatment (Figure $6 \mathrm{I}-\mathrm{B}(\mathrm{b})$ ). The decrease of the bands attributed to $\mathrm{Mg}$-species in less pronounced in the region $1800-600 \mathrm{~cm}^{-1}$, although it is noteworthy the slight shift of the Si-O stretching band at higher wavenumber, which confirms the formation of amorphous silica formed after the partial solution of the tetrahedral sheet [26].

Similar observations can be made in the $\mathrm{O}-\mathrm{H}$ stretching region after the treatment of $\mathrm{Mg}$-smectite with $\mathrm{Fe}^{3+}$ solutions (Fe-Sm) (Figure 6II-A,II-B). The unique difference is the displacements of the Si-O stretching band from 963 to $994 \mathrm{~cm}^{-1}$. This result suggests that the presence of oxohydroxides of Fe in the interlayer of $\mathrm{Mg}$-smectite affect the $\mathrm{Si}-\mathrm{O}$ stretching out-of-plane vibrational modes.

In the case of the sample $\mathrm{Fe}-\mathrm{Sm}-\mathrm{H}$, the $\mathrm{O}-\mathrm{H}$ stretching region of DRIFT spectra shown the appearance of a wide band from 3700 to $2700 \mathrm{~cm}^{-1}$ overlapping the small bands at 3681 and $3614 \mathrm{~cm}^{-1}$ observed in the DRIFT spectra of Sm-H. Moreover, and intense water bending band at $1633 \mathrm{~cm}^{-1}$ and the higher intensity of the spectra from 900 to $700 \mathrm{~cm}^{-1}$ suggest of a great amount of water molecules coordinated to oxohydroxides of Fe supported at the external surfaces of the lamellar particles.

The hydroxyl-stretching region of the DRIFT spectra of the starting sepiolite sample (Sp) is shown in Figure 7I-A. In this region, sepiolite shows two bands at 3689 and $3619 \mathrm{~cm}^{-1}$ which are associated with the stretching vibration of the hydroxyls coordinated with magnesium; a band at $3560 \mathrm{~cm}^{-1}$ related with the stretching modes of molecular water coordinated with magnesium, and two bands at 3360 and $3242 \mathrm{~cm}^{-1}$ that have been attributed to zeolitic and coordinated water [33,34].

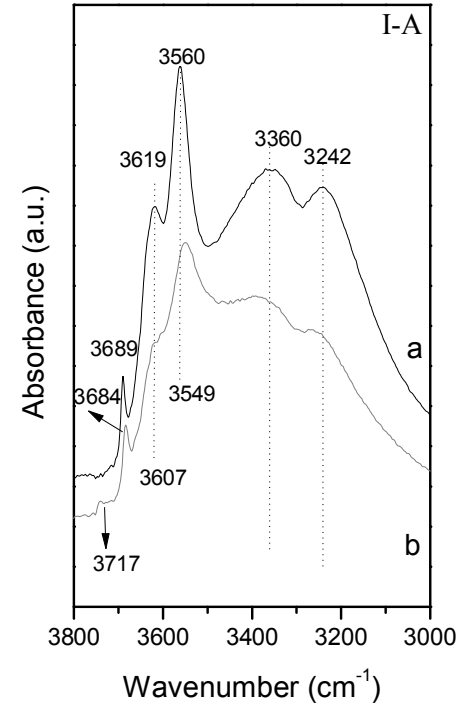

Wavenumber $\left(\mathrm{cm}^{-1}\right)$

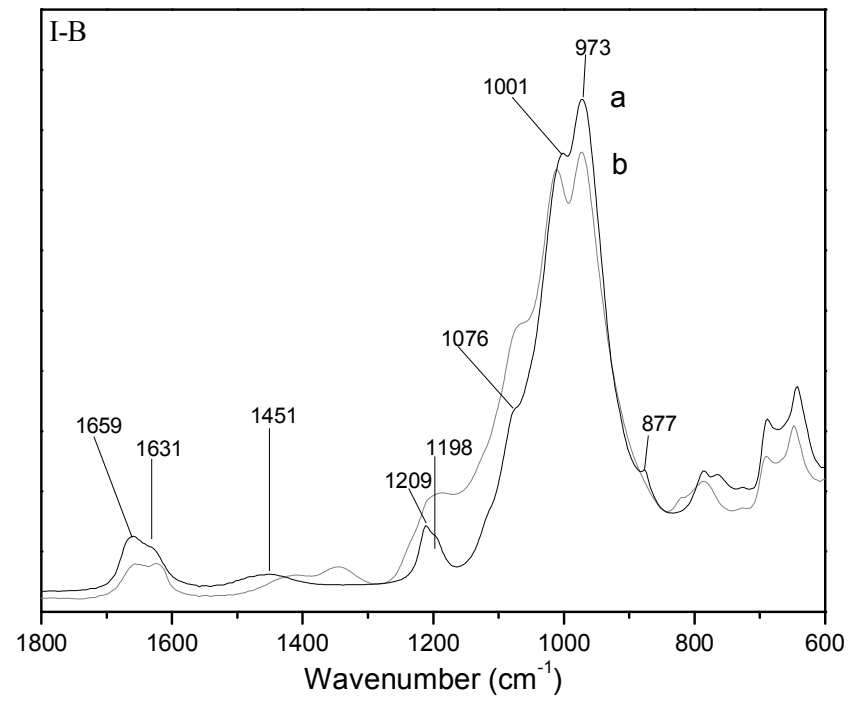

Figure 6. Cont. 

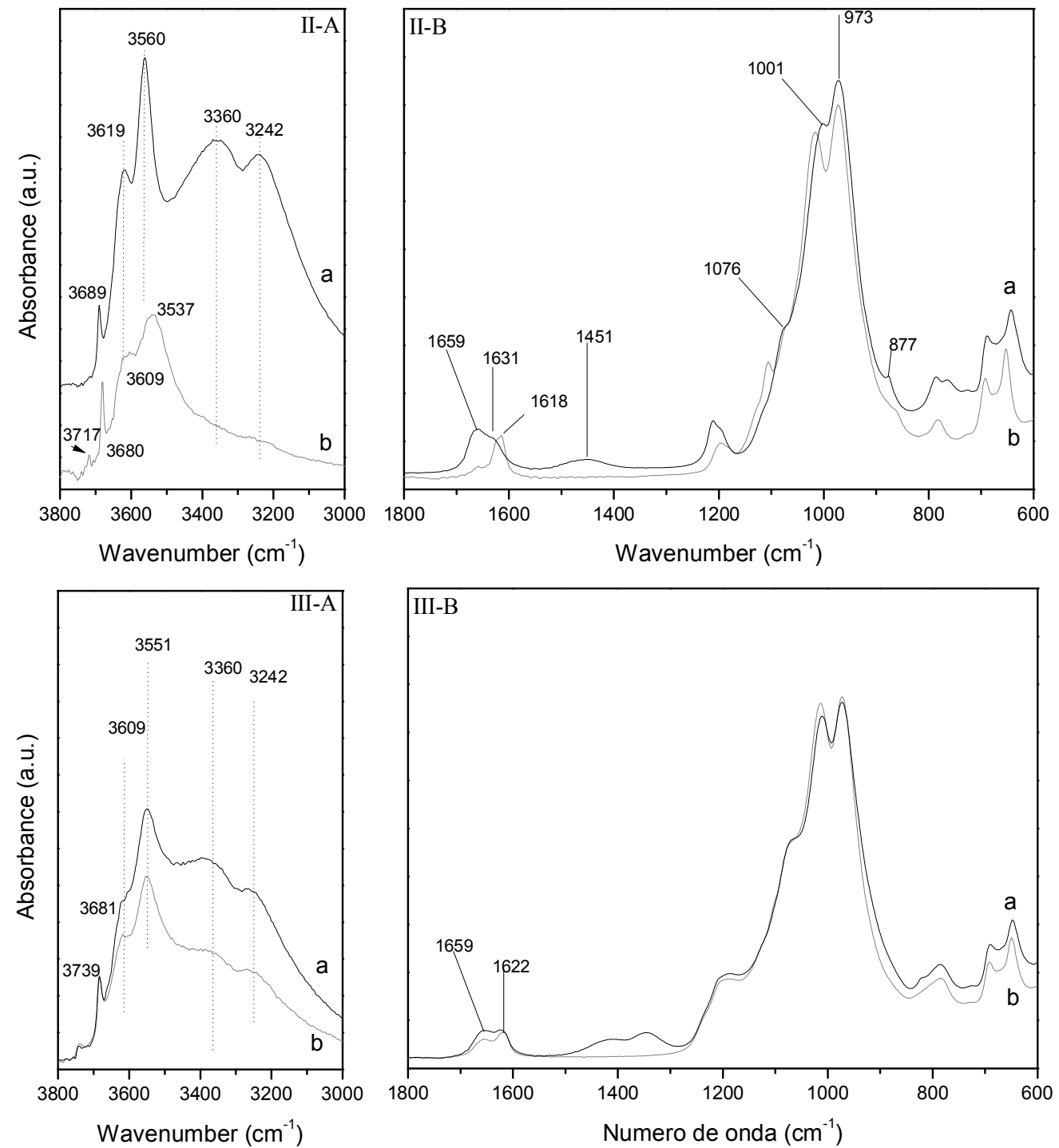

Figure 6. (I) Comparison of DRIFT spectra of natural Sm (A) vs. Sm-H (B, grey); (II) comparison of DRIFT spectra of natural Sm (A) vs. Fe-Sm (B, grey) and (III) comparison of DRIFT spectra of Sm-H (A) vs. Fe-Sm-H (B, grey). 

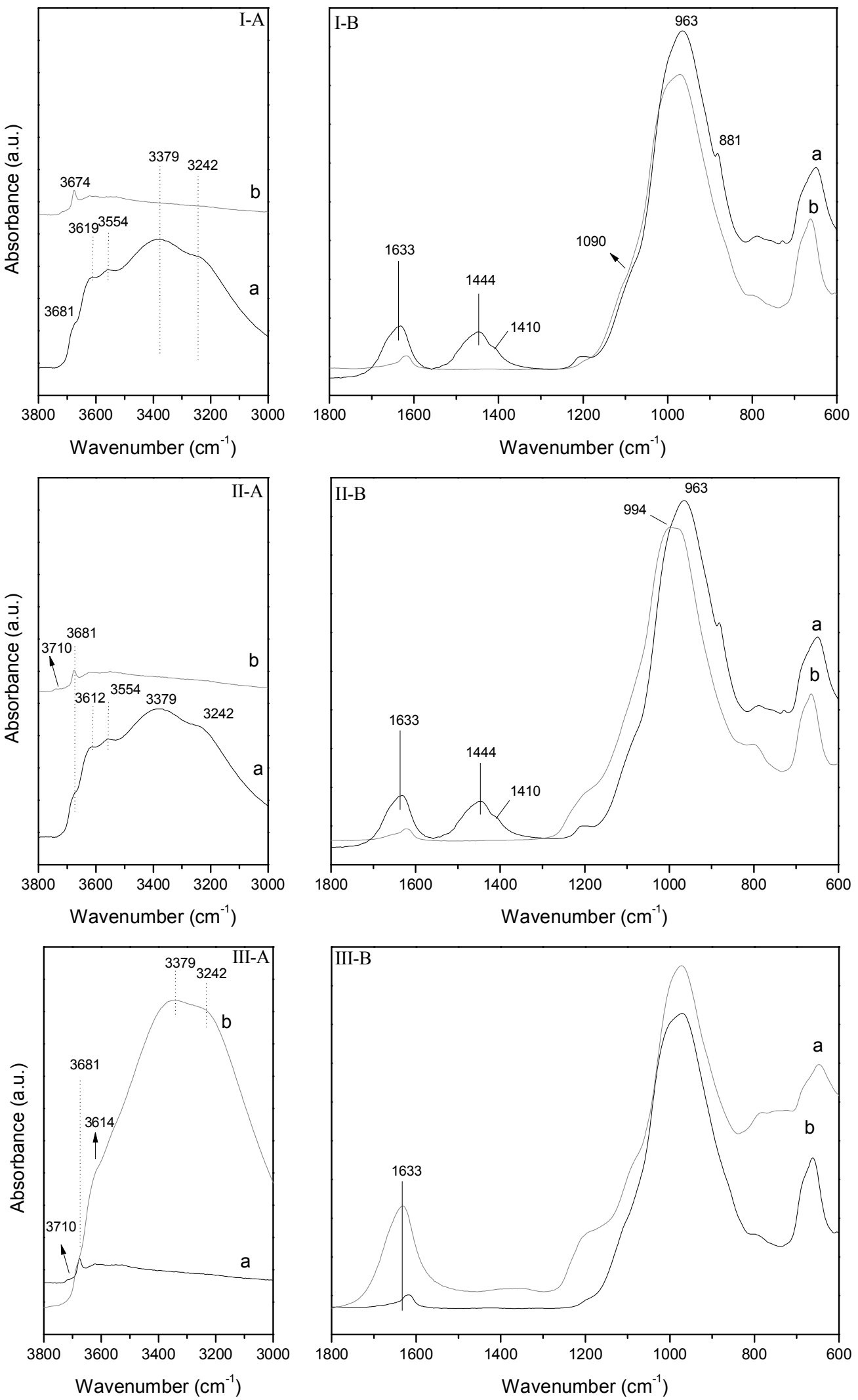

Figure 7. (I) Comparison of DRIFT spectra of natural Sepiolite (A) vs. Sp-H (B, red); (II) comparison of DRIFT spectra of natural Sepiolite (A), Fe-Sp (B, grey) and (III) comparison of DRIFT spectra of Sp-H (A) vs. Fe-Sp-H (B, grey). 
Figure 7I-B shows a comparison between the raw sepiolite and the sepiolite modified by microwave assisted acid treatment. The $\mathrm{Si}-\mathrm{O}$ stretching region of the DRIFT spectra of natural sepiolite. According to Frost et al., bands at 1209, 1076, 1001, and $973 \mathrm{~cm}^{-1}$ are assigned to $\mathrm{Si}-\mathrm{O}$ stretching modes, whereas band at $877 \mathrm{~cm}^{-1}$ are attributed to $\mathrm{Mg}-\mathrm{OH}$ deformation and translation modes [32]. In other hand bands at 1659 and 1631 are attributed to these bands can be attributed to the zeolitic and adsorbed water, respectively [30], and band at $1451 \mathrm{~cm}^{-1}$ to the presence of carbonates [30].

The microwave assisted acid treatment $(\mathrm{Sp}-\mathrm{H})$ causes a drastic decreasing of the water stretching bands and $\mathrm{O}-\mathrm{H}$ stretching bands (Figure 7I-B). These later are also broadened and shifted to lower wavenumbers. At the same time the $\mathrm{Si}-\mathrm{O}$ bands are progressively widened to higher wavenumber causing a significant change in the profile of the DRIFT spectrum. In addition, it is noticeable the presence of a new band about $800 \mathrm{~cm}^{-1}$ as well as the shift of the $\mathrm{Si}-\mathrm{O}$ stretching bands at higher wavenumber values, which confirms the formation of amorphous silica after the acid treatment, as other authors have previously indicated [26,35].

Similar observations can be made in the $\mathrm{O}-\mathrm{H}$ stretching region after the treatment of sepiolite with $\mathrm{Fe}^{3+}$ solutions (Figure 7II-A,II-B). Nevertheless, in this case, despite the acidity of the Fe solution and the decrease in intensity of the $\mathrm{O}-\mathrm{H}$ bands suggesting the partial dissolution of the octahedral sheets, a minor amount of amorphous silica is observed.

In the case of the sample $\mathrm{Fe}-\mathrm{Sp}-\mathrm{H}$, the $\mathrm{O}-\mathrm{H}$ stretching region of DRIFT spectra shows scarce modifications when compared with the DRIFT of Sp-H. The only observed modifications are those related with a new decreasing of $\mathrm{O}-\mathrm{H}$ stretching and water stretching bands.

\subsection{Batch Adsorption Results}

The adsorption capacity of the clay mineral-based materials as a function of time is shown in Figure 8. These data reveals that the methylene blue adsorption on Mg-smectite-based materials is extremely fast, reaching equilibrium conditions after the first minutes. This result indicates the existence of a fast cationic exchange between the cations and methylene blue molecules. Although the adsorption on the external surface of the smectite particles plays an important role, the higher adsorption capacity of smectites compared with sepiolite suggests that a great proportion of methylene blue molecules are adsorbed between adjacent 2:1 layers of Mg-bentonite. These adsorption sites are very accessible since adjacent sheets are easily expanded in contact with the water molecules, favoring the introduction of the methylene blue in the interlayer space. Once the active sites are saturated, it has not been observed an increase of the methylene blue adsorption along the time.
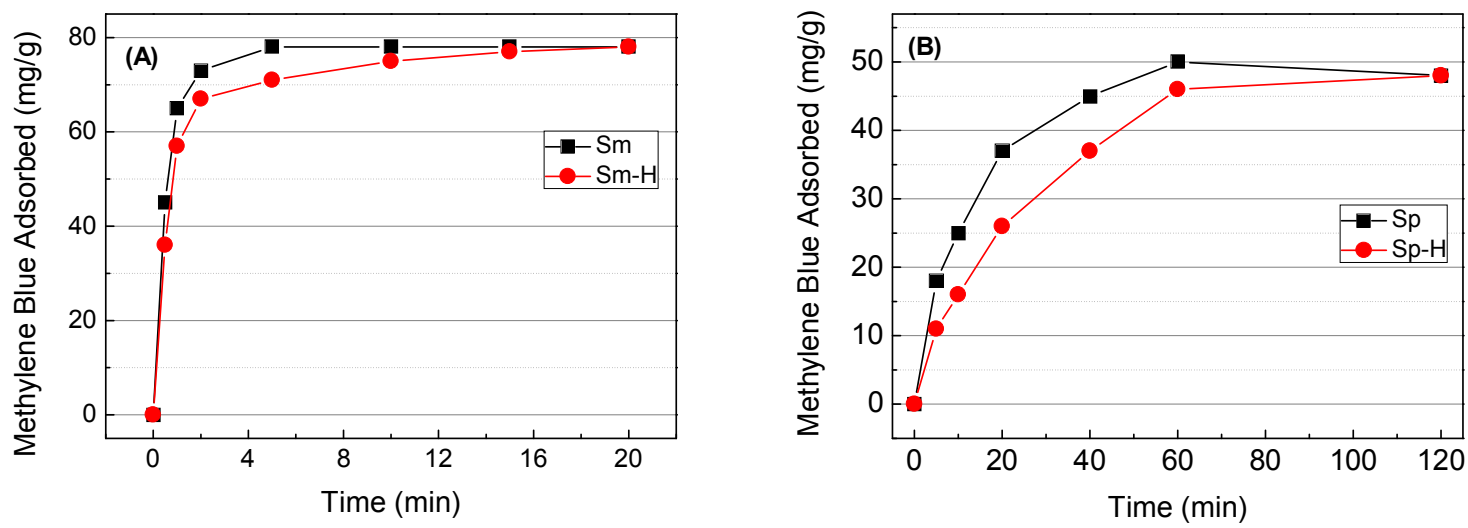

Figure 8. Kinetics of methylene blue adsorption in natural Mg-smectite ( $\mathrm{Sm})(\mathbf{A})$ and sepiolite (Sp) (B), and in the acid activated materials.

In the case of the sepiolite-based materials (Figure 8), about 60 minutes are required to reach the equilibrium conditions. The absence on linearity in the adsorption process suggests the existence of 
several adsorption sites. Thus, methylene blue molecules are easily adsorbed on the external surface of the fibers, while the adsorption in fibers aggregates takes place slowly by the existence of lower porosity. The methylene blue adsorption in the structural microchannels must be discarded due to the dimensions of the methylene blue ( $17 \AA \times 7,6 \AA \times 3.25 \AA$ ), which are higher than the dimensions of the structural channels in the sepiolite $(10.6 \AA \times 3.6 \AA)$ [36].

The use of microwave-assisted acid treatment modifies the adsorption kinetics. Thus, Mg-smectite reveals that the acid treatment slightly slows the adsorption rate in the first minutes (Figure 9). This change in the adsorption kinetics suggests that some of the new adsorption sites, generated after the acid treatment, display $\mathrm{H}^{+}$species adsorbed on the active sites, which slows the adsorption of methylene blue molecules, since $\mathrm{H}^{+}$species have higher affinity by the active centers than methylene blue cations.
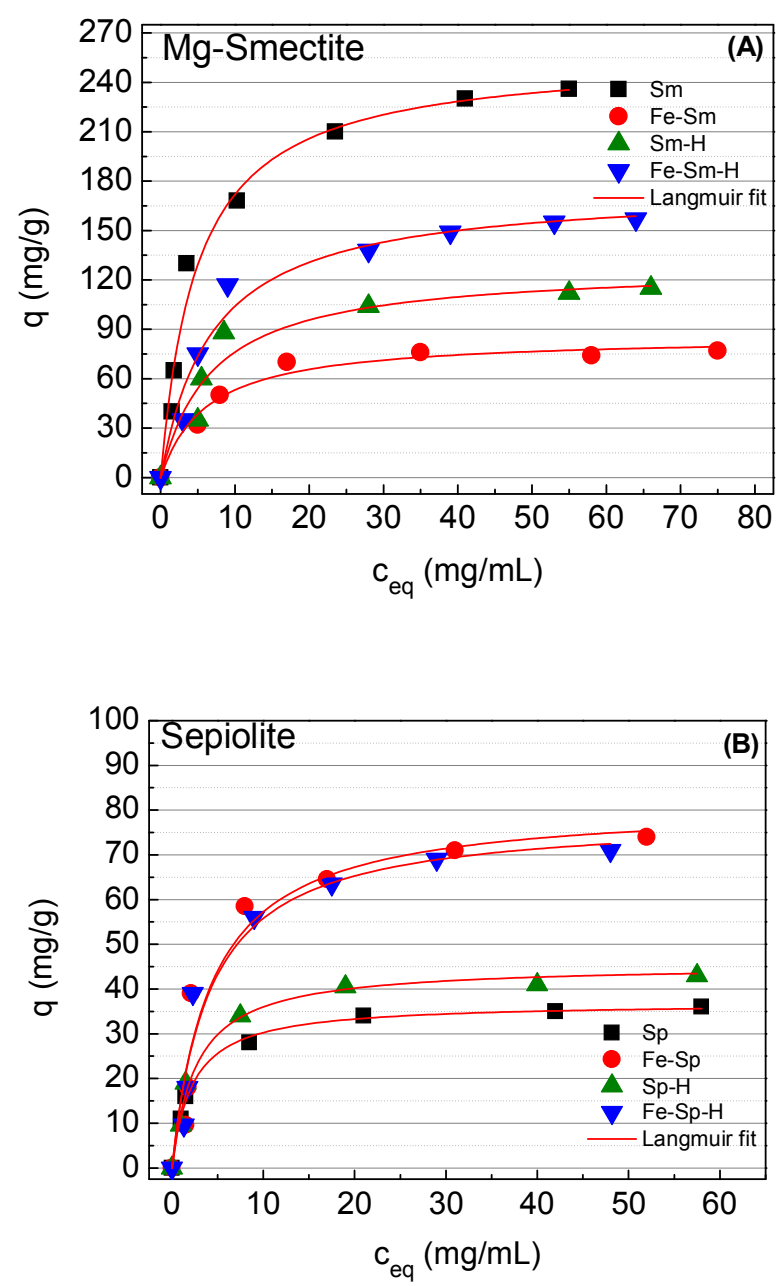

Figure 9. Experimental adsorption isotherms of methylene blue adsorption in Sm (A) and Sp (B), and in the obtained materials.

The microwave-assisted acid treatment of the raw sepiolite shows a similar effect in the adsorption kinetics to those observed in Mg-smectite (Figure 8) since the methylene adsorption is low at short and medium times, although after $120 \mathrm{~min}$ both materials reach similar values.

Considering the adsorption kinetics, an adsorption time of $20 \mathrm{~min}$ was chosen for the adsorption isotherms of $\mathrm{Sm}$, while the adsorption isotherms were carried out after $120 \mathrm{~min}$ for the sepiolite-based materials.

In all cases, the adsorption isotherms were well-fitted to the Langmuir model [37]. This elemental adsorption model assumes that occurs up to the formation of a monolayer, where a methylene 
blue molecule is adsorbed per each active site. In addition, these sites have the same binding energy, which supposes a homogeneous surface with no interactions between neighboring molecules. The Langmuir model is defined by the following equation:

$$
q=\frac{q_{m} \times\left(K_{L} \times c_{e q}\right)}{1+K_{L} \times c_{e q}}
$$

where $q$ is the amount of methylene blue adsorbed per unit weight $\left(\mathrm{mg} \cdot \mathrm{g}^{-1}\right), c_{e q}$ is the concentration of methylene blue in the liquid phase at adsorption equilibrium $\left(\mathrm{mg} \cdot \mathrm{mL}^{-1}\right), K_{L}$ is the dissociation constant of Langmuir $\left(\mathrm{mL} \cdot \mathrm{mg}^{-1}\right)$ that is associated with the energy of adsorption, and $q_{m}$ is the saturation capacity per unit weight $\left(\mathrm{mg}^{\circ} \mathrm{g}^{-1}\right)$.

Although the Langmuir model [37] supposes that all adsorption sites have the same binding energy we must to take into account that this is a simplification of the reality since the starting minerals have different adsorption sites with different environments and, moreover, these differences are accentuated with the different treatments tested. However, we assume this simplification since it allows an adequate comparison of adsorbent properties. The adsorption data of the Sm-based material are compiled in Figure 9A. From this figure, it can be observed how the raw Sm displays the highest adsorption capacity, reaching a $q_{m}$ value of $256 \mathrm{mg}$ methylene blue $\mathrm{g}^{-1}\left(0.80 \mathrm{mmol} \cdot \mathrm{g}^{-1}\right)$. Considering that the $\mathrm{Mg}$-smectite displays a cationic exchange capacity (CEC) of $0.87 \mathrm{~m}$ eq $\cdot \mathrm{g}^{-1}$, the obtained values are slightly smaller to the theoretical one. The modification of the Sm by microwave-assisted acid treatment $(\mathrm{Sm}-\mathrm{H})$ cause a clear decrease in the adsorption capacity, obtaining a $q_{m}$ value of only $128 \mathrm{mg} \cdot \mathrm{g}^{-1}$. This fact can be attributed to the acid treatment leads to loss of the active sites, by the disappearance of $-\mathrm{OH}$ groups coordinated with $\mathrm{Mg}$ species, which are leached in the acid treatment and the formation of amorphous silica. The decrease of the adsorption capacity after the acid treatment could also assigned to a proportion of cations located in the interlayer spacing can be replaced by $\mathrm{H}^{+}$species, which have higher affinity by the active sites. In this sense, the $K_{L}$ data, that defines the interaction adsorbate-adsorbent, reveals that the $\mathrm{K}_{\mathrm{L}}$ data of the raw $\mathrm{Mg}$-smectite is higher in comparison to the material treated with acid, which can confirm the presence of $\mathrm{H}^{+}$that diminish the affinity with the methylene blue molecules.

The methylene blue adsorption of the Mg-smectite decreases even more when iron oxohydroxides species are incorporated in its interlayer spacing (Figure 9A), which led to the formation a pillared and rigid structure, as was suggested from the 001 reflection shown in the XRD data (Figure 3I). This fact limits the expansion of the interlayer spacing to retain methylene blue in aqueous medium, obtaining a $q_{m}$ value of 86 and $176 \mathrm{mg} \cdot \mathrm{g}^{-1}$ for Sm-Fe and $\mathrm{Fe}-\mathrm{Sm}-\mathrm{H}$, respectively (Table 3). With regard to the affinity defined by $K_{L}$ value, in both cases the affinity is lower to that observer for the raw material, probably due to the increase of rigidity of the pillared structure that avoids the expansion of the interlayer spacing, limiting the amount of available active sites.

The adsorption isotherms of the sepiolite-based adsorbents are shown in Figure 9B. In the case of the raw sepiolite (Sp) the $q_{m}$ adsorption is only of $37 \mathrm{mg}$ of methylene blue $\mathrm{g}^{-1}\left(0.12 \mathrm{mmol} \cdot \mathrm{g}^{-1}\right)$ (Table 3$)$. These values are well below the CEC $\left(37 \mathrm{meq} \cdot \mathrm{g}^{-1}\right)$, which can be expected since the methylene blue molecular is too bulky to access the small zeolitic channels of sepiolite. From these data it can be inferred that the adsorption capacity is directly related with the structure of both materials since the adsorption capacity of the septiolite is five times lower to that observed for the raw $\mathrm{Mg}$-smectite. On the one hand, $\mathrm{Mg}$-smectite $(\mathrm{Sm})$ can adsorb methylene blue on its external surface as well as in the interlayer space since the interlayer space can expand to accommodate the methylene blue cations. On the other hand, the rigid structure of sepiolite (Sp) and the cross-section of its channels, smaller than the dimension of the methylene blue cation. This limits the adsorption to the external surface of sepiolite fibers exclusively. The modification of the raw sepiolite by acid treatment causes a slight increase of the adsorption capacity, reaching a $q_{m}$ value of $45 \mathrm{mg} \cdot \mathrm{g}^{-1}$, although the $\mathrm{S}_{\text {BET }}$ value increases in higher proportion (from 308 to $400 \mathrm{~m}^{2} \cdot \mathrm{g}^{-1}$ ) (Table 3). This increasing of the $\mathrm{S}_{\mathrm{BET}}$ value is related to both the dispersion of fibers making accessible new active centers for adsorption and the formation 
of amorphous silica phase without active centers. Thus, only a part of the new generated $S_{\mathrm{BET}}$ has the ability to adsorb methylene blue cations. For this reason, the increasing of adsorption capacity is notably lower than the increasing of $S_{\text {BET }}$.

Table 3. Adsorption data obtained from Langmuir Adsorption Isotherm.

\begin{tabular}{|c|c|c|c|c|c|}
\hline \multicolumn{4}{|c|}{ Langmuir } & \multicolumn{2}{|c|}{ Langmuir } \\
\hline \multirow{3}{*}{ Sp } & $q_{m}$ & $36.981 \pm 4.310$ & \multirow{3}{*}{$\mathrm{Sm}$} & $q_{m}$ & $256.469 \pm 12.197$ \\
\hline & $K_{L}$ & $0.450 \pm 0.021$ & & $K_{L}$ & $0.203 \pm 0.015$ \\
\hline & $r^{2}$ & 0.99692 & & $r^{2}$ & 0.98004 \\
\hline \multirow{3}{*}{$\mathrm{Fe}-\mathrm{Sp}$} & $q_{m}$ & $81.543 \pm 6.481$ & \multirow{3}{*}{$\mathrm{Fe}-\mathrm{Sm}$} & $q_{m}$ & $85.914 \pm 7.815$ \\
\hline & $K_{L}$ & $0.235 \pm 0.012$ & & $K_{L}$ & $0.162 \pm 0.009$ \\
\hline & $r^{2}$ & 0.94195 & & $r^{2}$ & 0.97163 \\
\hline \multirow{3}{*}{$\mathrm{Sp}-\mathrm{H}$} & $q_{m}$ & $45.471 \pm 4.415$ & \multirow{3}{*}{$\mathrm{Sm}-\mathrm{H}$} & $q_{m}$ & $128.452 \pm 6.489$ \\
\hline & $K_{L}$ & $0.3801 \pm 0.024$ & & $K_{L}$ & $0.1458 \pm 0.008$ \\
\hline & $r^{2}$ & 0.98978 & & $r^{2}$ & 0.9297 \\
\hline \multirow{3}{*}{$\mathrm{Fe}-\mathrm{Sp}-\mathrm{H}$} & $q_{m}$ & $78.651 \pm 5.852$ & \multirow{3}{*}{$\mathrm{Fe}-\mathrm{Sm}-\mathrm{H}$} & $q_{m}$ & $175.902 \pm 8.521$ \\
\hline & $K_{L}$ & $0.244 \pm 0.011$ & & $K_{L}$ & $0.144 \pm 0.007$ \\
\hline & $r^{2}$ & 0.95833 & & $r^{2}$ & 0.96971 \\
\hline
\end{tabular}

Unlike to that observed in Mg-smectite, the incorporation of iron oxohydroxides species into both $\mathrm{Sp}$ and $\mathrm{Sp}-\mathrm{H}$ clearly improves the methylene blue adsorption capacity, reaching a $q_{m}$ values of 82 and $79 \mathrm{mg} \cdot \mathrm{g}^{-1}$ for Fe-Sp and Fe-Sp-H, respectively. Nonetheless, the isotherms report that the affinity of these sites are lower to those shown in the case of the starting sepiolite, as indicates the $K_{L}$ value (Table 3). This remarkable increasing in the adsorption capacities are not in line with the decreasing in $\mathrm{S}_{\mathrm{BET}}$, mainly decreasing of micropore surface, observed with the Fe-treatment (Table 2). This decreasing the micropore surface is related to the steric impediment generated by iron species within the channels of Sepiolite. However, taking into account that the methylene blue adsorption in Sepiolite occurs exclusively at the external surface of fibers, the formation of new adsorption centers due to the presence of iron oxohydroxides species can explain the increasing of adsorption capacities.

\section{Conclusions}

The present study evaluates the adsorption capacity of two clay minerals with different morphologies. These clays are a Mg-smectite, which is formed by stacked sheets, and a sepiolite with fibrous structure and small channels inside of its structure.

This study have shown that, in the starting clay samples, the adsorption capacities of methylene blue is markedly related with the structural characteristics of both minerals. The higher adsorption capacity of the Mg-smectite compared with the sepiolite is related to the ability of Mg-smectite to expand basal spacing and accommodate methylene blue cations, whereas, in sepiolite, the lower cation exchange capacity, as well as the cross-section of the structural channels, prevents the entry of these cations. Thus in Mg-smectite the adsorption of methylene blue occurs in both the interlayer positions and at the external surface of lamellar particles. While, in sepiolite the adsorption of methylene blue is limited at the external surface of fibers exclusively.

The modification of the Mg-smectite by microwave-assisted acid treatment cause a clear decrease in the adsorption capacity attributed to the partial loss of the interlayer positions by the loss of the octahedral sheet and subsequent formation of amorphous silica without active centers. Moreover, the methylene blue adsorption of the $\mathrm{Mg}$-smectite decreases even more when iron oxohydroxides species are incorporated in its interlayer spacing forming a rigid pillared structure with a fixed 
interlayer space which is smaller than the methylene blue cation size. Thus, this structural modification makes inaccessible the interlayer active sites for this cation.

On the contrary, the microwave-assisted acid treatment of sepiolite causes a slight increase in the adsorption capacity related with the dispersion of fibers. Nevertheless, contrary to that observed with Mg-Smectite, greater increases of adsorption capacities were obtained after the formation of new adsorption centers due to the incorporation of iron oxohydroxides species at the external surfaces of sepiolite.

Author Contributions: M.P. provided the samples for this work. F.F., M.P., and V.H. conceived and designed the experimental research and reviewed background research. C.L.M. and M.J.B. supervised data acquisition and compilation. L.P. and J.A.C. carried out the experiments, data reduction, and calculations. All authors contributed to the interpretation of the results as well as writing and editing of the paper. The authors have approved the submitted version and agree to be personally accountable for the author's own contributions and for ensuring that questions related to the accuracy or integrity of any part of the work, even ones in which the author was not personally involved, are appropriately investigated, resolved, and documented in the literature.

Funding: This research received no external funding.

Acknowledgments: The authors are very grateful for the inestimable help of the reviewers who have significantly improved the article. The authors wish to thank the project BIA2017-82391-R for the financial support. The preparation of this paper is included within the activities of the RNM-199 (Universidad de Málaga) and C-144 (Universidad Autónoma de Madrid, Geomaterials and Geological Processes) Research Groups.

Conflicts of Interest: The authors declare no conflicts of interest. The founding sponsors had no role in the design of the study; in the collection, analyses, or interpretation of data; in the writing of the manuscript, and in the decision to publish the results.

\section{References}

1. İyim, T.B.; Güçlü, G. Removal of basic dyes from aqueous solutions using natural clay. Desalination 2009, 249, 1377-1379.

2. Kabra, A.N.; Khandare, R.V.; Waghmode, T.R.; Govindwar, S.P. Phytoremediation of textile effluent and mixture of structurally different dyes by Glandularia Pulchella (Sweet). Chemosphere 2012, 87, 265-272. [CrossRef] [PubMed]

3. Auta, M.; Hameed, B.H. Coalesced chitosan activated carbon composite for batch and fixed-bed adsorption of cationic and anionic dyes. Colloids Surf. B 2013, 105, 199-206. [CrossRef] [PubMed]

4. Leodopoulos, C.; Doulia, D.; Gimouhopoulos, K. Adsorption of cationic dyes onto bentonite. Sep. Purif. Rev. 2014, 44, 74-107. [CrossRef]

5. Yagub, M.T.; Sen, T.K.; Afroze, S.; Ang, H.M. Dye and its removal from aqueous solution by adsorption: A review. Adv. Colloid Interface Sci. 2014, 209, 172-184. [CrossRef] [PubMed]

6. Vaccari, A. Clays and catalysis: A promising future. Appl. Clay Sci. 1999, 14, 161-198. [CrossRef]

7. Abbassi, R.; Yadav, A.K.; Kumar, N.; Huang, S.; Jaffe, P.R. Modeling and optimization of dye removal using "green" clay supported iron nanoparticles. Ecol. Eng. 2013, 61, 366-370. [CrossRef]

8. Borisover, M.; Davis, J.A. Adsorption of inorganic and organic solutes by clay minerals. Dev. Clay Sci. 2015, 6, 33-70.

9. Bailey, S.W. Structures of layer silicates. In Crystal Structures of Clay Minerals and their X-ray Identification; Mineralogical Society: London, UK, 1984; pp. 1-123.

10. Benlikaya, R.; Alkan, M.; Kaya, I. Preparation and characterization of sepiolite-poly (ethyl methacrylate) and poly (2-hydroxyethyl methacrylate) nanocomposites. Polym. Compos. 2009, 30, 1585-1594. [CrossRef]

11. Jones, B.F.; Galán, E. Sepiolite and Palygorskite. Miner. Soc. Am. 1988, 19, 631-674.

12. Galán, E.; Carretero, M.I. A new approach to compositional limits for sepiolite and palygorskite. Clays Clay Miner. 1999, 47, 399-409.

13. Galarneau, A.; Barodawalla, A.; Pinnavaia, T.J. Porous clay heterostructures formed by gallery, -templated synthesis. Nature 1995, 374, 529-531. [CrossRef]

14. Cecilia, J.A.; García-Sancho, C.; Franco, F. Montmorillonite based porous clay heterostructures: Influence of $\mathrm{Zr}$ in the structure and acidic properties. Microporous Mesoporous Mater. 2013, 176, 95-102. [CrossRef]

15. Al-Khatib, L.; Fraige, F.; Al-Hwaiti, M.; Al-Khashman, O. Adsorption from aqueous solution onto natural and acid activated bentonite. Am. J. Environ. Sci. 2012, 8, 510-522. [CrossRef] 
16. Toor, M.; Jin, B.; Daí, S.; Vimonses, V. Activating natural bentonite as a cost-effective adsorbent for removal of Congo-red in wastewater. J. Ind. Eng. Chem. 2015, 21, 653-661. [CrossRef]

17. Franco, F.; Pozo, M.; Cecilia, J.A.; Benítez-Guerrero, M.; Pozo, E.; Martín-Rubí, J.A. Microwave assisted acid treatment of sepiolite: The role of composition and "crystallinity". Appl. Clay Sci. 2014, 102, 15-27. [CrossRef]

18. Franco, F.; Pozo, M.; Cecilia, J.A.; Benítez-Guerrero, M.; Lorente, M. Effectiveness of microwave assisted acid treatment on dioctahedral and trioctahedral smectites. The influence of octahedral composition. Appl. Clay Sci. 2016, 120, 70-80. [CrossRef]

19. Vilarrasa-García, E.; Cecilia, J.A.; Bastos-Neto, M.; Cavalcante, C.L.; Azevedo, D.C.S.; Rodríguez-Castellón, E. Microwave-assisted nitric acid treatment of sepiolite and functionalization with polyethylenimine applied to $\mathrm{CO}_{2}$ capture and $\mathrm{CO}_{2} / \mathrm{N}_{2}$ separation. Appl. Surf. Sci. 2017, 410, 315-325.

20. Franco, F.; Benítez-Guerrero, M.; Gonzalez-Triviño, I.; Pérez-Recuerda, R.; Assiego, C.; Cifuentes-Melchor, J.; Pascual-Cosp, J. Low-cost aluminum and iron oxides supported on dioctahedral and trioctahedral smectites: A comparative study of the effectiveness on the heavy metal adsorption from water. Appl. Clay Sci. 2016, 119, 321-332. [CrossRef]

21. Hang, P.T.; Brindley, G.W. Methylene blue absorption by clay minerals. Determination of surface areas and cation exchange capacities (Clay-organic studies XVIII). Clays Clay Miner. 1970, 18, 203-212. [CrossRef]

22. Küncek, I.; Şener, S. Adsorption of methylene blue onto sonicated sepiolite from aqueous solutions. Ultrason. Sonochem. 2010, 17, 250-257.

23. Korichi, S.; Elias, A.; Mefti, A. Characterization of smectite after acid activation with microwave irradiation. Appl. Clay Sci. 2009, 42, 432-438. [CrossRef]

24. Brunauer, S.; Emmett, P.H.; Teller, E. Adsorption of gases in multimolecular layers. J. Am. Ceram. Soc. 1938, 60, 309-319. [CrossRef]

25. Madejová, J. FTIR techniques in clay mineral studies. Vib. Spectrosc. 2003, 31, 1-10.

26. Lippens, B.C.; De Boer, J.H. Studies on pore systems in catalysts: V. The t method. J. Catal. 1965, 4, 319-323. [CrossRef]

27. Van der Marel, H.W.; Beutelspacher, H. Atlas of Infrared Spectroscopy of Clay Minerals and Their Admixtures; Elsevier: Amsterdam, The Nertherlands, 1976.

28. Kloprogge, J.T.; Frost, R.L. Thermal decomposition of Ferrianchamosite: An infrared emission spectroscopic study. Contrib. Mineral. Petrol. 2000, 138, 59-67. [CrossRef]

29. Zviagina, B.B.; McCarty, D.K.; Srodon, J.; Drits, V.A. Interpretation of infrared spectra of dioctahedral smectites in the region of OH-stretching vibrations. Clay Clay Miner. 2004, 52, 399-410. [CrossRef]

30. Farmer, V.C. The Layer Silicates. In The Infrared Spectra of Minerals; Mineralogical Society: London, UK, 1974; pp. 331-363.

31. Johnston, C.T.; Premachandra, G.S. Polarized ATR-FTIR Study of Smectite in Aqueous Suspension. Langmuir 2001, 17, 3712-3718. [CrossRef]

32. Komadel, P.; Madejová, J. Acid activation of clay minerals. Dev. Clay Sci. 2006, 1, 265-289.

33. Frost, R.L.; Locos, O.B.; Ruan, H.; Kloprogge, J.T. Near-infrared and mid-infrared spectroscopic study of sepiolites and palygorskites. Vib. Spectrosc. 2001, 27, 1-13. [CrossRef]

34. Frost, R.L.; Cash, G.A.; Kloprogge, J.T. "Rocky Mountain leather", sepiolite and attapulgite-an infrared emission spectroscopic study. Vib. Spectrosc. 1998, 16, 173-184. [CrossRef]

35. Valentín, J.L.; López-Manchado, M.A.; Rodríguez, A.; Posadas, P.; Ibarra, L. Novel anhydrous unfolded structure by heating of acid pre-treated sepiolite. Appl. Clay Sci. 2007, 36, 245-255.

36. Raya, J.; Hirschinger, J.; Ovarlez, S.; Giulieri, F.; Chazeb, A.M.; Delamare, F. Insertion of indigo molecules in the sepiolite structure as evidenced by 1H-29Si heteronuclear correlation spectroscopy. Phys. Chem. Chem. Phys. 2010, 12, 14508-14514. [CrossRef] [PubMed]

37. Langmuir, I. The adsorption of gases on plane surfaces of glass, mica and platinum. J. Am. Chem. Soc. 1918, 40, 1361-1403. [CrossRef]

(C) 2018 by the authors. Licensee MDPI, Basel, Switzerland. This article is an open access article distributed under the terms and conditions of the Creative Commons Attribution (CC BY) license (http:/ / creativecommons.org/licenses/by/4.0/). 